\title{
POTENSI KEANEKARAGAMAN SATWA LIAR (MAMALIA DAN REPTIL) DI KAWASAN HUTAN TAMAN WISATA ALAM KERANDANGAN
}

\author{
THE POTENTIALS OF (WILDLIFE (MAMALIA AND REPTIL) DIVERSITY \\ IN THE FOREST AREA OF KERANDANGAN NATURAL TOURISM PARK
}

oleh

\author{
Emilianus Yodi Kebu, Lalu Suhirsan Masrilurrahman, Hafizah Nahlunnisa \\ Program Studi Kehutanan Universitas Pendidikan Mandalika \\ Email : 1.suhirsan.ms@gmail.com
}

\begin{abstract}
Biodiversity potential of wild animals (mammals and reptiles) in the Natural Tourism Park (TWA) Kerandangan is a potential that is complex and must be conserved. mammals and reptiles in the Kera TWA Forest Area. In this scientific paper uses literature study methods and field studies and data analysis techniques based on a comparison of dominance indexes. The author can conclude that the group of mammals (Lutung Trachypithecus auratus, Cercopithecidae family found in the 3 lanes such as the gray monkey Macaca Fascicularis, tree rats, Rattus tiomanicus, and Weasels, Paradoxurus, reptile groups (Snakes, there are two types of snakes found in the gray monkey Macaca Fascicularis, tree rats, Rattus tiomanicus, and Weasels, Paradoxurus, reptile groups (snakes) Sibynophis and Trimerusus insularis species, Gekko Gecko Gecko, Lacetillia Lizard, and aquatic monitor lizards and lizards of Varanus Salvator and Varanus Macraei species and species diversity index on lane $1=1.641$, medium category, lane $2=1.431$ moderate category and lane 3 and 1.23 lane Varaus Salvator and Varanus Macraei. moderate category Animal density from all 3 mammal and reptile pathways is 2,431.
\end{abstract}

Kata kunci: hutan rakyat,vegetasi, indeks nilai penting dan keanekaragaman jenis.

\section{Abkstrak}

Potensi keanekaragaman hayati Satwa liar (Mamalia dan Reptil) di Taman Wisata Alam (TWA) Kerandangan merupakan potensi yang bersifat komplek dan harus dilestarikan oleh karena itu Fokus penelitian ini adalah untuk mengkaji jenis satwa, indeks keanekaragaman jenis satwa liar mamalia dan reptil, serta Bagaimana kepadatan satwa mamalia dan reptil di Kawasan Hutan TWA Kerandangan. Dalam Karya Tulis ilmiah ini menggunakan Metode kajian pustaka dan Studi Lapangan dan teknik analisis data berdasarkan perbandingan indeks Dominansi. Penulis dapat menyimpulkan bahwa Kelompok mamalia (Lutung Trachypithecus auratus, famili Cercopithecidae yang di temukan dari ke 3 jalur seperti Monyet abu- abu Macaca Fascicularis, Tikus pohon ,Rattus tiomanicus, Dan Musang, Paradoxurus, Kelompok reptil (Ular ada dua jenis ular di temukan yaitu jenis Sibynophis dan Trimerusus insularis, Tokek Gekko Gecko, Kadal Lacetillia, Dan Biawak air dan biawak pohon Varanus Salvator dan Varanus Macraei dan Indeks keanekaragaman jenis pada jalur 1=1,641 yaitu kategori sedang ,pada jalur $2=1,431$ kategori sedang dan pada jalur $3=1,267$ kategori sedang Kepadatan satwa dari ke 3 jalur mamalia dan reptil adalah 2,431.

\section{PENDAHULUAN}

Indonesia merupakan negara yang kaya dengan kehidupan liar (wild life), yang terdiri dari fauna (satwa) dan flora, termasuk keragaman speciesnya, serta komunitas ekologis darat, laut dan air dimana mereka berada, misalnya hutan tropis, hutan beriklim sedang, danau air tawar, lahan basah dan sebagainya. Kekayaan tersebut dikenal sebagai Keanekaragaman hayati (biological diversity). (Sukanda Husin, 2009).

Keberadaan kekayaan keanekaragaman hayati berada dalam suatu ancaman kepunuhan 
disebabkan oleh tingkah laku dan keserakahan manusia terutama dalam upaya memburu peradabannya (Maurice Sunkin, David M. Ong dan Robert Wight 1998).

Satwa liar adalah binatang yang hidup didalam ekositem alam. Pola pengelolah satwa liar telah berkembang dengan pesat, bukan saja untuk keperluan perlindungan tetapi juga pemanfaatan lestar. Pemanfaatan satwa liar ini meliputi untuk kegiatan penelitian, pendidikan pariwiasata, rekreasi. Pada kenyataan satwa liar memiliki nilaidan manfaatbagi kehidupan manusia, maka ruang lingkup pengelolahnya harus di perluar (Ikrar,2011).

Keanekaragaman jenis yang tinggi menunjukkan bahwa suatu komunitas memiliki kompleksitas yang tinggi.. Salah satu hutan lindung yang ada di Pulau Lombok yaitu Taman Wisata Alam (TWA) Kerandangan. Pada saat ini, informasi mengenai keanekaragaman satwa liar yang terdapat di kawasan Taman Wisata Alam Kerandangan masih belum memadai. Untuk itu perlu dilakukan kegiatan inventarisasi, sehingga dapat membantu dalam penyediaan data yang diperlukan. (Endang, Tri. 2010)

Kekayaan keanekaragaman hayati sangat penting keberadaannya bagi manusia karena dia merupakan sumber kehidupan, baik berupa makanan maupun obat-obatan dan sumber genetika. Disamping itu, keanekaragaman hayati juga berguna bagi lingkungan hidup sendiri yaitu untuk saling menopang sistem kehidupan dalam satu ekosistem. (Sukanda Husin, William J. Snape,., 1996).

Keberadaan kekayaan keanekaragaman hayati berada dalam suatu ancaman kepunuhan disebabkan oleh tingkah laku dan keserakahan manusia terutama dalam upaya memburu peradabannya. (Maurice Sunkin, David M. Ong dan Robert Wight, 1998).

Dalam memburu peradabannya, manusia sering merubah hutan atau lahan pertanian menjadi kawasan industri atau perumahan. Perbuatan ini menimbulkan akibat fatal karena di hutan yang dijadikan lahan perindustrian itu bisa jadi terdapat beberapa jenis tumbuhan yang berguna untuk dijadikan bahan dasar untuk mengobati penyakit tertentu. Ada enam penyebab utama berkurangnya atau punahnya species atau habitat sebagai bagian dari kekayaan keanekaragaman hayati, yaitu:

1. pertumbuhan penduduk dan meningkatnya konsumsi atas sumberdaya alam baik hayati maupun non-hayati;
2. pengabaian species dan ekosystem;

3. kebijaksanaan yang jelek;

4. efek dari sistem perdagangan global;

5. ketidakseimbangan distribusi sumberdaya; dan

6. kegagalan memberi nilai terhadap keanekaragaman hayati Philippe Sands, op. cit., Hal. 369.).

\section{METODOLOGI PENELITIAN}

\section{a. Waktu dan Tempat Penelitian}

Penelitian ini di mulai pada bulan Januari dan berlokasi di kawasan hutan TWA Kerandangan, Desa Senggigi, Kecamatan Batu layar, Kabupaten Lombok Utara.

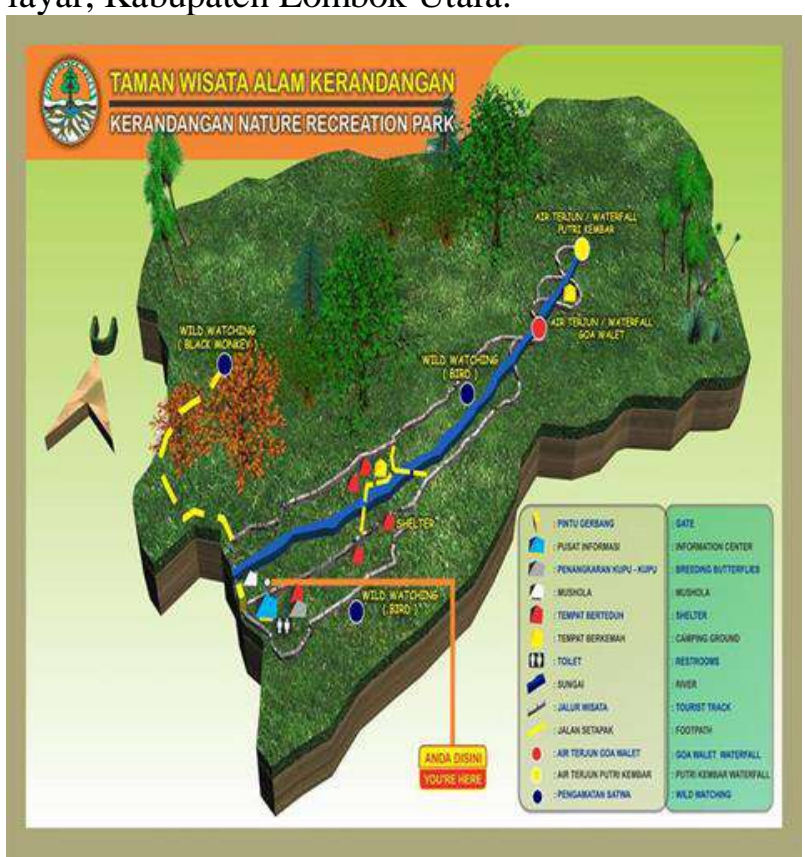

Gambar 1. Peta TWA Kerandangan (BKSDA NTB 2018)

\section{b. Bahan}

Alat dan bahan yang di gunakan dalam penelitian ini terdiri dari semua peralatan untuk pengamatan satwa liar serta peralatan dokumentasi pada saat penelitian. Dokumentasi di perlukan untuk membantu peneliti dalam menyelesaikan pengelolahan data setelah di kumpulkan pada saat penelitian di lapangan. Alat yang digunakan adalah: Alat tulis (untuk Menulis data penelitian Taly shet (Menulis data penelitian), Gps (Menentukan titik pengamatan), Kamera (mendokumentasi data penelitian), Peta (untuk mengetahui lokasi). 


\section{c. Jenis Data}

Jenis Data yang di gunakan dalam penelitian ini adalah data primer dan data skunder. Data primer adalah data yang di peroleh langsung dari lapangan atau lokasi penelitian seperti dokumentasi dan data lain. Sedangkan data skunder adalah data yang diambil dari sumber data tidak langsung yaitu melalui studi pustaka berupa buku-buku, dokumen, karya ilmiah serta artikel dari internet.

\section{d. Teknik Pengumpulan Data}

Teknik pengumpulan data tentang potensi karagaman satwa liar mamalia dan reptil di kawasan hutan Taman Wisata Alam Kerandangan dilakukan dengan menggunakan metode jalur dikombinasikan dengan metode titik hitung dilakukan dengan berjalan menelusuri jalur sampai pada titik berikutnya dan selanjutnya mencatat semua jenis satwa, mamalia dan reptil yang ditemukan dalam jalur pengamatan. Contoh peletakan jalur pengamatan.

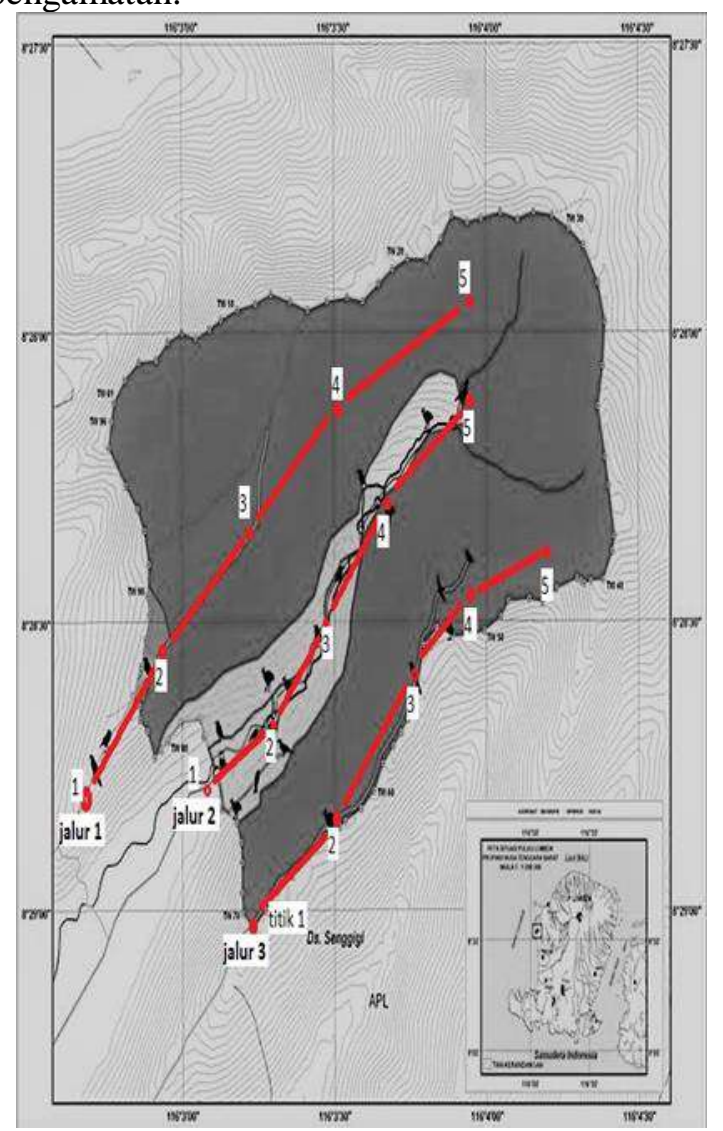

Gambar 2. Jalur Pengamatan (Birdwatching Taman Kerandangan)

\section{e. Metode Analisis}

Metode yang digunakan untuk menganalisis keanekaragaman komunitas antara lain melalui pendekatan berdasarkan perbandingan indeks Dominansi (Odum, 1983) yaitu : Indeks dominansi $(\mathrm{C})$

$$
C=\Sigma\left(\frac{n i}{N}\right)^{2}
$$

Keterangan:

$\mathrm{ni}=$ Jumlah individu suatu jenis

$\mathrm{N}=$ Jumlah individu seluruh jenis

$\mathrm{C}=$ Keanekaragaman Jenis

Indeks kekayaan jenis dengan menggunakan rumus Shannon dan Wiener (1988)

$$
\begin{array}{r}
\mathrm{H}^{=}=-\sum \hat{\mathrm{P}} \boldsymbol{L n} \boldsymbol{P} \llbracket \\
\boldsymbol{n} \boldsymbol{i} \\
\operatorname{dimna:} \boldsymbol{P}- \\
\boldsymbol{n}
\end{array}
$$

Keterangan:

$\mathrm{H}^{\prime}=$ Indeks keanekaragaman

$\mathrm{ni}=$ Jumlah individu satu jenis

$\mathrm{N}=$ Jumlah Idividu seluruh jenis

Selanjutnya kriteria tingkat keanekaragaman berdasarkan nilai indeks keanekaragaman adalah sebagai berikut

$\mathrm{H}^{\prime}<1$ = Tingkat keanekaragaman rendah

$1<\mathrm{H}^{\prime}<3=$ Tingkat keanekaragaman sedang $\mathrm{H}^{\prime}>3=$ Tingkat keanekaragaman tinggi

Analisis untuk menghitung Kepadatan Satwa dengan menggunakan rumus sebagai berikut:

$$
\hat{D}=\frac{n}{2 L w}
$$

Keterangan:

$\mathrm{D}=$ Kepadatan populasi (Jumlah individu/ha)

$\mathrm{n}=$ jumlah satwa yang teramati

$\mathrm{L}=$ panjang total transek

$\mathrm{w}=$ lebar transek

\section{HASIL dan PEMBAHASAN}

Indeks Dominasi (C'), satwa (mamalia dan reptil) pada ke 3 jalur dapat dihitung dengan menggunakan indeks Dominasi (Odum 1983). Nilai (C') bertujuan untuk mengetahui Dominansi suatu jenis. Pada tabel jalur 1 di bawah ini menunjukan Indeks Dominansi (C') pada Kawasan Taman Wisata Alam Kerandangan. 
Tabel 1. Indeks Dominansi

\begin{tabular}{llllll}
\hline No & Nama Satwa & Nama Ilmiah & Ni & P & C \\
\hline 1 & Lutung & $\begin{array}{l}\text { Trachypithecus } \\
\text { auratus }\end{array}$ & 12 & 0,413 & 0,171 \\
\hline 2 & $\begin{array}{l}\text { Monyet Abu- } \\
\text { Abu }\end{array}$ & $\begin{array}{l}\text { Macaca } \\
\text { Fascicularis }\end{array}$ & 6 & 0,222 & 0,049 \\
\hline 3 & Biawak Air & Varanus Salvator & 1 & 0,037 & 0,001 \\
\hline 4 & Musang & $\begin{array}{l}\text { Paradoxurus } \\
\text { Hermaphroditus }\end{array}$ & 1 & 0,037 & 0,001 \\
\hline 5 & Kadal & Lacetillia & 5 & 0,185 & 0,034 \\
\hline 6 & Tokek & Gekko Gecko & 2 & 0,074 & 0,005 \\
\hline 7 & Ular & Sibynophis & 2 & 0,074 & 0,005 \\
\hline & Jumlah Total & & $\mathbf{2 9}$ & $\mathbf{1 , 0 4 3}$ & \\
\hline & & & & &
\end{tabular}

Dari tabel di atas dapat diketahui bahwa spesies yang memiliki nilai Indeks Dominansi Tertinggi yaitu spesies Lutung Trachypithecus auratus Famili Cercopithecidae Ordo Primates dengan jumlah individu adalah $12\left(\mathrm{C}^{\prime}=0,171\right)$ dan Monyet Abu-Abu Macaca Fascicularis Famili Cercopithecidae Ordo Primata dengan jumlah individu adalah $6\left(C^{\prime}=0,049\right)$ sedangkan spesies yang memiliki nilai indeks Dominansi terendah yaitu spesies Biawak Air Varanus Salvator Famili varanidae Ordo Squamata dengan junlah individu $=1\left(C^{\prime}=0,001\right)$.

Indeks keanekaragaman satwa (mamalia dan reptil) pada ke 3 jalur dapat dihitung dengan menggunakan indeks keanekaragaman ShannonWienner. Nilai (H') bertujuan untuk mengetahui presentase keanekaragaman suatu jenis dalam suatu ekosistem. Parameter yang menentukan nilai indeks keanekaragaman pada ekosistem ditentukan oleh jumlah spesies dan kelimpahan relatif jenis pada suatu komunitas. Pada tabel jalur 1 di bawah ini menunjukan Indeks Keanekaragaman pada Kawasan Taman Wisata Alam

Tabel 2. Indeks keanekaragaman

\begin{tabular}{cllllll}
\hline No & $\begin{array}{l}\text { Nama } \\
\text { Satwa }\end{array}$ & Nama Ilmiah & Ni & P & Ln p & H' \\
\hline 1 & Lutung & $\begin{array}{l}\text { Trachypithecus } \\
\text { auratus }\end{array}$ & 12 & 0,413 & $-0,882$ & 0,365 \\
\hline \multirow{2}{*}{$\begin{array}{l}\text { Monyet } \\
\text { Abu- } \\
\text { Abu }\end{array}$} & $\begin{array}{l}\text { Macaca } \\
\text { Fascicularis }\end{array}$ & 6 & 0,222 & $-1,504$ & $\mathbf{0 , 3 3 4}$ \\
\hline 3 & $\begin{array}{l}\text { Biawak } \\
\text { Air }\end{array}$ & $\begin{array}{l}\text { Varanus } \\
\text { Salvator }\end{array}$ & $\mathbf{1}$ & $\mathbf{0 , 0 3 7}$ & $-3,296$ & $\mathbf{0 , 1 2 2}$ \\
\hline 4 & Musang & $\begin{array}{l}\text { Paradoxurus } \\
\text { Hermaphroditus }\end{array}$ & $\mathbf{1}$ & 0,037 & $-3,296$ & 0,122 \\
\hline 5 & Kadal & Lacetillia & 5 & 0,185 & $-1,686$ & 0,312 \\
\hline 6 & Tokek & Gekko Gecko & 2 & 0,074 & $-2,602$ & 0,192 \\
\hline 7 & Ular & Sibynophis & 2 & 0,074 & $-2,602$ & 0,192 \\
\hline & $\begin{array}{l}\text { Jumlah } \\
\text { Total }\end{array}$ & $\mathbf{2 9}$ & $\mathbf{1 , 0 4 3}$ & $\mathbf{1 5 , 8 7 0}$ & $\mathbf{1 , 6 4 1}$ \\
\hline
\end{tabular}

Dari tabel di atas dapat diketahui bahwa spesies yang memiliki nilai Indeks Keanekaragaman Tertinggi yaitu spesies Lutung Trachypithecus auratus Famili Cercopithecidae Ordo Primates jumlah individu sebanyak 12 dengan indeks keanekaragaman jenis $=0,365$ dan
Monyet Abu-Abu Macaca Fascicularis Famili Cercopithecidae Ordo Primata dengan jumlah individu sebanyak $=6$ dengan indeks keanekaragaman jenis $=0,334$ sedangkan spesies yang memiliki nilai indeks keanekaragaman terendah yaitu spesies Biawak Air Varanus Salvator Famili varanidae Ordo Squamata dengan jumlah individu sebanyak $=1$ dengan indeks keanekaragaman jenis $=0,122$. Dan Musang Paradoxurus Hermaphroditus Famili viverridae Ordo Carnivora dengan jumlah individu sebanyak $=1$ dengan indeks keanekaragaman jenis $=0,122$. Total Indeks Keanekaragaman pada jalur 1 adalah $=1,641$. Termasuk sedang karena menurut Shannon dan Wiener kriteria sedang karena berada antara diatas 1 dan di bawah 3 .

Kepadatan populasi satwa liar mamalia dan reptil (D'), satwa (mamalia dan reptil) pada ke 3 jalur ini dapat dihitung dengan menggunakan rumus kepadatan. Nilai (D') bertujuan untuk mengetahui presentase kepadatan dalam suatu wilayah. Parameter yang menentukan nilai Kepadatan (D') pada ekosistem ditentukan oleh jumlah spesies dan kelimpahan relatif jenis pada ke 3 jalur Pada tabel di bawah ini menunjukan bahwa Kepadatan Satwa mamalia dan reptil pada 3 jalur yaitu pada Kawasan Taman Wisata Alam Kerandang

Tabel 3. Kepadatan Populasi

\begin{tabular}{|c|l|c|c|c|c|c|c|c|}
\hline \multirow{2}{*}{ No } & \multirow{2}{*}{ Nama Satwa } & \multicolumn{2}{|c|}{ Transek } & \multicolumn{2}{c|}{$\begin{array}{c}\text { Jumlah } \\
\text { Satwa }\end{array}$} & $\begin{array}{c}\text { P } \\
\text { (L)m }\end{array}$ & $\begin{array}{c}\text { L } \\
\text { (W)m }\end{array}$ & $\begin{array}{c}\text { Kepadatan } \\
\text { Populasi }\end{array}$ \\
\cline { 3 - 7 } & 1 & 2 & 3 & & & 15 & 0,7 \\
\hline 1 & $\begin{array}{l}\text { Monyet abu }- \\
\text { abu }\end{array}$ & 6 & 10 & 5 & 21 & 1500 & 10 & 0 \\
\hline 2 & Lutung & 12 & 9 & 9 & 30 & 1500 & 10 & 1 \\
\hline 3 & Biawak & 1 & 1 & 0 & 2 & 1500 & 10 & 0,066 \\
\hline 4 & Musang & 1 & 0 & 0 & 1 & 1500 & 10 & 0,033 \\
\hline 5 & Kadal & 5 & 3 & 1 & 9 & 1500 & 10 & 0,3 \\
\hline 6 & Tokek & 2 & 0 & 0 & 2 & 1500 & 10 & 0,066 \\
\hline 7 & Ular & 2 & 2 & 2 & 6 & 1500 & 10 & 0,2 \\
\hline 8 & Tikus pohon & 0 & 1 & 1 & 2 & 1500 & 10 & 0,066 \\
\hline Jumlah total & 29 & 26 & 18 & 73 & & & 2,431 \\
\hline
\end{tabular}

Kepadatan Satwa yang yang di jumpai dari 3 jalur di kawasan Taman wisata Alam Kerandangan dengan urutan kepadatannya adalah:

Kelompok mamalia

a) Lutung Trachypithecus auratus, famili Cercopithecidae yang di temukan dari ke 3 jalur sebanyak 30 ekor dengan kepadatannya adalah 1

b) Monyet abu- abu Macaca Fascicularis yang di temukan dari ke 3 jalur yaitu sebanyak 21 ekor dengan kepadatannya adalah 0,7 
c) Tikus pohon ,Rattus tiomanicus, ditemukan sebanyak 2ekor dengan kepadatannya adalah 0,066

d) Musang, Paradoxurus Hermaphroditus ditemukan sebanyak 1 ekor dengan kepadatannya adalah 0,033

Kelompok reptil

1. Ular ada dua jenis ular di temukan yaitu jenis Sibynophis di temukan sebanyak 4 ekor dan Trimerusus insularis sebanyak 2 ekor dengan kepadatannya adalah 0,2

2. Tokek Gekko Gecko yang ditemukan sebanyak 2 ekor dengan kepadatannya adalah 0,066

3. Kadal Lacetillia di temukan sebanyak 9 ekor dengan kepadatannya adalah 0,3

4. Biawak air dan biawak pohon Varanus Salvator dan Varanus Macraei yang di temukan sebanyak 2 ekor dengan kepadatannya adalah 0,066

\section{KESIMPULAN}

Berdasarkan penelitian dihasilkan kesimpulan bahwa jenis-jenis potensi satwa liar mamalia dan reptil di Taman Wisata Kerandangan adalah: Kelompok mamalia (Lutung Trachypithecus auratus, famili Cercopithecidae yang di temukan dari ke 3 jalur sebanyak 30 ekor, Monyet abu- abu Macaca Fascicularis yang di temukan dari ke 3 jalur yaitu sebanyak 21 ekor, Tikus pohon ,Rattus tiomanicus, ditemukan sebanyak 2 ekor, Dan Musang, Paradoxurus Hermaphroditus ditemukan sebanyak 1 ekor). Kelompok reptil (Ular ada dua jenis ular di temukan yaitu jenis Sibynophis di temukan sebanyak 4 ekor dan Trimerusus insularis sebanyak 2 ekor, Tokek Gekko Gecko yang ditemukan sebanyak 2 ekor, Kadal Lacetillia di temukan sebanyak 9 ekor, Dan Biawak air dan biawak pohon Varanus Salvator dan Varanus Macraei yang di temukan sebanyak 2 ekor. Indeks keanekaragaman jenis pada jalur 1=1,641 yaitu kategori sedang ,pada jalur $2=1,431$ kategori sedang dan pada jalur 3 $=1,267$ kategori sedang. Kepadatan satwa dari ke 3 jalur mamalia dan reptil adalah 2,431

\section{DAFTAR PUSTAKA}

Akmal, Y., Nisa, C., \& Novelina, S. (2019). Morfologi Kelenjar Aksesori Kelamin Jantan pada Trenggiling (Manis javanica) (Morphology Of The Male Sex Accessory Glands Of The Pangolin (Manis javanica)).
Jurnal Veteriner, 20(36), 38-47. https://doi.org/10.19087/jveteriner.2020 .2 $\underline{0.1 .38}$

Alikodra, H. S. 2002. Pengelolaan Satwaliar Jilid 2. Buku. Yayasan Penerbit Fakultas Kehutanan Institut Pertanian Bogor. Bogor. $363 \mathrm{hlm}$.

Alikodra,S Hadi Teknik pengelolah satwa liar IPB Press Mei 2010

Ani Mardiastuti dan Tommy Soehartono, Pelaksanaan Konvensi

Bapennas. 1993. Laporan kerja BAPPENAS. Badan Perencanaan dan

Campbell. 2012. Buku Ajar Biologi. Buku. Penerbit Erlangga. Jakarta. $501 \mathrm{hlm}$.

Campbell. 2012. Buku Ajar Biologi. Buku. Penerbit Erlangga. Jakarta. $501 \mathrm{hlm}$.

CITES di Indonesia, Japan

Cox MJ, Dijk P van, Nabhitabhata J, Thirakhupt K. 1998. A Photographic Guideto Snakes and Other Reptiles of Peninsular Malaysia, Singapore and Thailand. London, Sidney, Singapore: New Holland Publishers Ltd.

Distributors. New Delhi. 125 hlm.

Duellman WE, Heatwole H. 1998. Di dalam: Cogger HG, RG Zweifel, editor.Encyclopedia of Reptiles and Amphibians. San Fransisco: Fog City Press.

Gaulke M, Abel F, Erdelen W, Fritz U. 1998. Notes on the Herpetofauna of North Sumatra. Hamadryad 23(1):78-82.

Gibbons JW, Scott DE, Ryan TJ, Buhlmann KA, Tuberville TC, Metts BS, Greene JL, Mills T, Leiden Y, Poppy S, Winne CT. 2000. The Global Decline of Reptiles Déjà vu Amphibians. Bioscience. (50) 8: 653-666.

Goin CJ, Goin OB. 1971. Introduction to Herpetology. San Francisco: WH Freeman and Company

Greene JL, Mills T, Leiden Y, Poppy S, Winne CT. 2000. The Global Decline of Reptiles Déjà vu Amphibians. Bioscience. (50) 8: 653-666.

Harmonis. 2005. Pelaksanaan prinsip-prinsip konvensi kehutanan dan keanekaragaman hayati ktt bumi rio de janeiro pada pengelolaan satwaliar di kalimantan timur. Rimba Kalimantan. 10(2): 71-80.

Indonesia, Undang-Undang tentang Kehutanan, UU Nomor 41 Tahun 1999, LN Tahun 1999 Nomor 167, TLN Nomor 3888.

international Cooperation Agency (JICA), 2003, hlm. 6.Indonesia, Keputusan Presiden Tentang Convention On International Trade In. Endangered Species Of Wild Fauna And 
Flora, Keppres No. 43 Tahun 1978, Lihat juga: Keppres No. 1 tahun1987 tentang Ratifikasi Konvensi CITES, Op.Cit.

IWGFF \& PPATK. Panduan Pelatihan Penyidikan Tindak Pidana Kehutanan melalui pendekatan anti korupsi dan anti pencucian uang (Jakarta; PPATKIWGFF.2012) hal. 28-29.

Jasin, M. 1984. Sistematik Hewan : (Invertebrata dan Vertebrata). Buku. Sinar Wijaya. Surabaya. $328 \mathrm{hlm}$.

Jenkins, B. 2002. Learning Mammalia. Buku. Dominant Publisher and

Kartono, A. P. 2015. Keragaman dan kelimpahan mamalia di perkebunan sawit pt sukses tani nusa subur kalimantan timur. Media Konservasi. 20(2):85-92.

Kartono, A. P., Maryanto, I., dan Jayasilan, M. A. 2003. Diversity of Big Mammals in Pa'Raye, Kayan Mentarang National Park, East Kalimantan. Buku. Joint Biodiversity Expedition in Kayan Mentarang National Park. Bogor. 152 hlm.

Mammals of Borneo. Buku. The Sabah Society. Sabah. $450 \mathrm{hlm}$.

Mattison C. 1992. Snakes of The World. New York: Facts on File Inc.

Mattison C. 2005. Encyclopedia of Reptiles and Amphibians. Singapore: The Brown Reference Group plc.Gibbons JW, Scott DE, Ryan TJ, Buhlmann KA, Tuberville TC, Metts BS,

Maurice Sunkin, David M. Ong dan Robert Wight, Sourcebook on Environmental Law, Cavendish Publishing Limited, London: 1998, Hal. 485.

menurut Pasal 1 Undang-Undang Nomor 5 Tahun 1990 Tentang Konservasi Sumber Daya Alam dan ekosistemnya

Mustari, A. H., Agus, S., dan Dones, R. 2015. Kelimpahan jenis mamalia menggunakan kamera jebakan di resort gunung botol taman nasional gunung harimun salak. Jurnal Media Konservasi. 20(2): 93-101.

Payne, J. C., Francis, M., dan Phillipps, K. 2000. A Field Guide to The

Pembangunan Nasional

Pokja Kebijakan Konservasi. Draft Naskah Akademis revisi UU No.5 tahun 1990. (Jakarta; Pokja Kebijakan Konservasi. 2014) hal.

Sudrajat. 2001. Keanekaragaman dan Ekologi Herpetofauna (Reptil dan Amfibi) di
Sumatera Selatan [skripsi]. Bogor: Fakultas Kehutanan. Institut Pertanian Bogor.

Sukanda Husin, Hukum Lingkungan Internasional, Buku Ajar, Pusbangdik Universitas Riau, Pekanbaru,2009, Hal

Sukiya. 2001. Biologi Vertebrata. Buku. JICA. Yogyakarta. $184 \mathrm{hlm}$.

Sunil, N. T., dan Sucheta, S. T. 2013. Comparative anatomy of knee joint : class amphibian (frog) versus class mamalia (human being). Scholars Journal of Applied Medical Sciences. 1(5): 560-567.

Suyanto, A. 2002. Mammalia di Taman Nasional Gunung Halimun Jawa Barat. Buku. Biodiversity Conservation Project. Bogor. $86 \mathrm{hlm}$.

Suyanto, A. dan Semiadi, G. 2004. Keragaman Mamalia di Daerah Sekitar Penyangga Taman Nasional Gunung Halimun, Kecamatan Cipanas, Kabupaten Lebak. Buku. Biodiversity Conservation Project. Bogor. 92 hlm.

UU Konservasi, Op. Cit., Pasal 5

Van Derlzon, A. P. M. 1979. Mammalia of Indonesia. Buku. Draft Version UNDP/FAO National Park Development Project. Bogor. $234 \mathrm{hlm}$.

Wilson, D. E., Russell, F., Nichols, J. D., Rudran. R., dan Foster. M. S. 1996. Measuring and Monitoring Biological Diversity, Standard Methods formMammals. Buku. Smithsonian Institution Press. London. 409 hlm. 